\title{
Schopf-Schulz-Passarge Syndrome: a Case Report on Rare Ectodermal Dysplasia
}

\author{
Authors \\ Abhishek Thakur ${ }^{1}$, Ravinder Singh ${ }^{2 *}$, Dilbag Singh ${ }^{3}$, Shikha Verma ${ }^{4}$ \\ ${ }^{1}$ Senior Resident, Department of DermatologyDr RKGMC Hamirpur H.P India \\ ${ }^{2}$ Medical Officer, Dermatology DR RKGMC Hamirpur H.P India \\ ${ }^{3}$ Senior Resident Dermatology JLNGMC Chamba HP India \\ ${ }^{4}$ Senior Resident Pediatrics Dr RPGMC Kangra at Tanda HP India \\ *Corresponding Author \\ Ravinder Singh
}

\begin{abstract}
Schopf-Schulz-Passarge syndrome (SSPS) is a rare type of ectodermal dysplasia characterized by palmoplantar keratoderma, hypodontia, hypotrichosis, nail dystrophy and multiple periocular and eyelid apocrine hidrocystomas. A 23-year-old female presented with eyelid hidrocystomas, palmoplantar keratoderma, nail dystrophy and thin scalp hair. Skin biopsy was consistent with apocrine hidrocystoma. The patient was diagnosed with SSPS.
\end{abstract}

\section{Introduction}

The ectodermal dysplasias (EDs) are a large and complex heterogeneous group of inherited diseases characterized by abnormal development of the tissues derived from embryonic ectoderm. The tissue primarily involved are skin and appendages (hair follicles, eccrine glands, sebaceous glands, and, nails) and teeth with or without anomalies in other organ systems. The incidence is estimated to be 7 in 10,000 births $^{[1]}$. Schöpf-Schulz-Passarge Syndrome is one of the rare ectodermal dysplasia syndrome characterized by multiple cysts on the eyelids, palmo-plantar keratoderma, hypodontia, hypotrichosis, and nail dystrophy ${ }^{[2]}$. As it includes the developmental abnormalities in teeth, hair and nails, SSPS was included in the heterogeneous group of ectodermal dysplasias with the name of tricho-odonto-onycho-dermal dysplasia ${ }^{[3]}$.
Moreover, although SSPS was originally described as an autosomal recessive condition, alternative patterns of inheritance have been proposed for single pedigrees ${ }^{[4]}$. While hypodontia can be diagnosed during childhood the hallmark of SSPS hidrocystomas of the eyelids, develop at an advanced age, and thus, SSPS may occasionally be under diagnosed $^{[5]}$.

\section{Case Report}

A 23-year-old female born to parents with nonconsanguineous marriage, presented to dermatology department with complains of thin and brittle nails with thickened and hard skin of palm and soles since her childhood. On examination koilonychia was observed in finger nails. The nails were thin and showed dystrophic appearance. The patient was in good general health and normal intelligence. 


\section{JMSCR Vol||08||Issue||06||Page 294-296||June}

Ichthyosis, dental anomalies and pigmentation were absent. Results of routine laboratory tests, including white blood cell count and granulocyte function, were normal. There were cystic swellings on lower eyelid of right eye. The lesions were painless with no history of oozing or bleeding from the lesion. The cysts were non-tender, firm inconsistency with a smooth surface. Skin biopsy from the ocular lesion was suggestive of apocrine hidrocystoma. Considering the clinical features of palmoplantar keratoderma, nail dystrophy, koilonychias and plat with histopathological findings of apocrine hidrocystomas the patient was diagnosed with Schopf-Schulz-Passarge syndrome (SSPS).
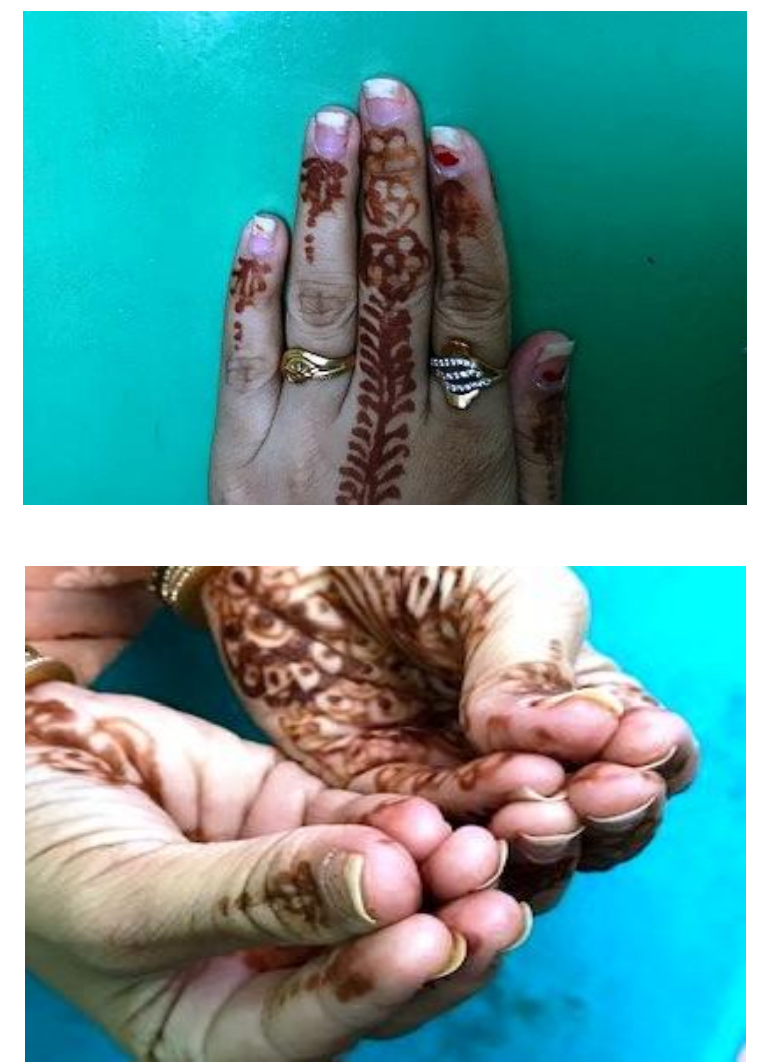

Figure 1, 2: Thinning of nails plates with nail dystrophy

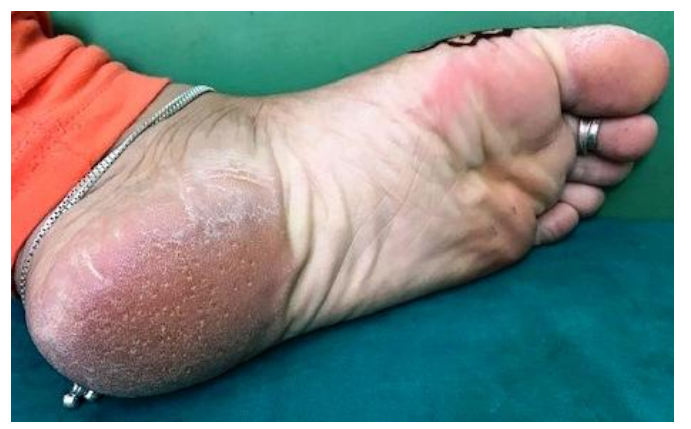

Figure 3: Planter Keratoderma

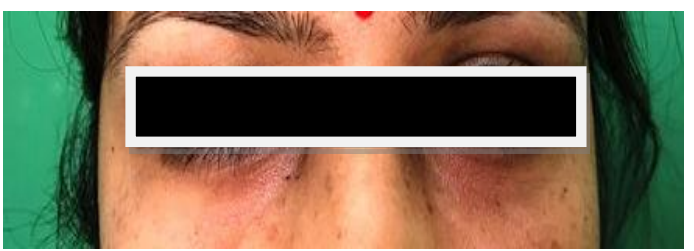

Figure 4: Eyelid Cyst

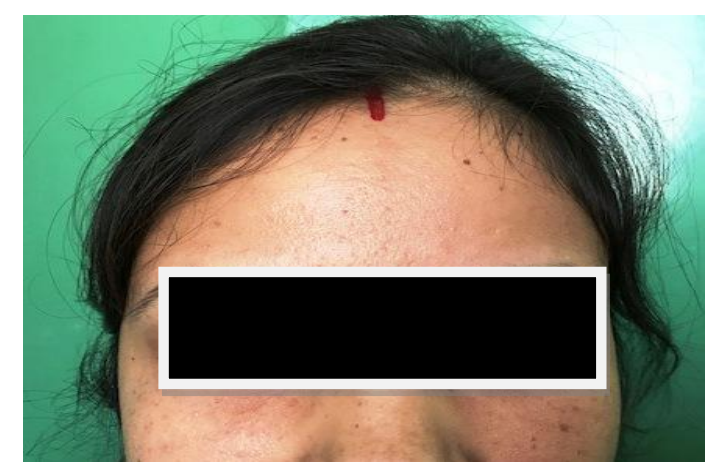

Figure 5: Thinning of Hairs

\section{Discussion}

SSPS is a rare type of ectodermal dysplasia which was first described in the year $1971^{[6]}$. It is characterized by palmoplantar keratoderma, hypodontia, hypotrichosis, nail dystrophy, and multiple periocular and eyelid apocrine hidrocystomas. The other features described are telangiectatic facial skin papules, multiple tumors with follicular differentiation, bilateral early senile cataract, arteriosclerotic fundi, optic atrophy, and myopia $^{[7]}$. The literature review demonstrates that the SSPS phenotypic spectrum is extremely variable, ranging from full-blown phenotypes to milder forms limited to palpebral and tooth involvement ${ }^{[8]}$. The most consistent feature of this syndrome is eyelid apocrine hidrocystoma which was seen in all the cases $(100 \%)$ described in literature $^{[9]}$. These lesions appear in adulthood and are asymptomatic causing the delay in diagnosis. However, the onset of hypotrichosis, palmoplantar keratoderma and nail dystrophy is reported to range from early childhood to early adulthood. While the deciduous dentition in SSPS can be normal, tooth agenesis within the permanent dentition can be diagnosed during the mixed dentition stage (age 612 years). The hypothesis that SSPS may be considered a cancer prone syndrome was originally introduced by Perret ${ }^{[10]}$. Despite the subsequent description of several cases with skin neoplasms, 
this association has never been sufficiently underlined. Genetic research has revealed that SSPS results from mutations in WNT10A gene located at $2 \mathrm{q} 35$. This gene acts as a principal signaling molecule for regulation of cell-cell interactions which are involved in multiple developmental processes in embryogenesis. It acts through inhibition of $\beta$-catenin degradation complex and is involved in tooth and hair follicle morphogenesis [11]. Our patient had eyelid apocrine cyst, palmoplantar keratoderma, nail dystrophy and hypotrichosis. Hence, the case was diagnosed with SSPS. There is no effective treatment for SSPS. Apocrine hidrocystomas can be treated with electrocautery. PPK can be treated with emollients and keratolytics. Nail and hair cosmesis may be provided for a concerned patient. Regular dental check-up and dental prosthesis must be provided to a patient. The clinical manifestations of ectodermal dysplasia can cause many social problems in the affected individuals. Psychological, social support, and genetic counselling should be offered to the patient.

\section{Reference}

1. Itin PH, Fistarol SK (2004) Ectodermal dysplasias. Am J Med Genet C Semin Med Genet 131:45-51.

2. Schopf E, Schulz HJ, Passarge E. Syndrome of cystic eyelids,palmo-plantar keratosis, hypodontia and hypotrichosis as a possible autosomal recessive trait. Birth Defects Orig Artic Ser 1971; 7: 219-221.

3. Freie-Maia N, Pinheiro M, editors. Ectodermal dysplasias: a clinical and genetic study. New York: Alan R. Liss, 1984.

4. Küster W, Hammerstein W. Schöpf syndrome. Clinical, genetic and lipid biochemical studies. Hautarzt 1992; 43:763766.

5. Castori M, Ruggieri S, Giannetti L, Annessi G, Zambruno G. Schopf-Schulz-Passarge syndrome: further delineation of the phenotype and genetic considerations. Acta Derm Venereol 2008; 88: 607-612.
6. Schopf E, Schulz HJ, Passarge E. Syndrome of cystic eyelids, palmo-plantarkeratosis, hypodontia and hypotrichosis as a possible autosomal recessive trait. Birth Defects Orig Artic Ser 1971;7:219-21.

7. Hampton PJ, Angus B, Carmichael AJ. A case of Schöpf-Schulz-Passarge syndrome. Clin Exp Dermatol 2005;30:528-30.

8. Monk BE, Pieris S, Soni V. Schöpf-SchulzPassarge syndrome. Br J Dermatol 1992; 127: 33-35.

9. Castori M, Ruggieri S, Giannetti L, Annessi G, Zambruno G. Schöpf-Schulz-Passarge syndrome: Further delineation of the phenotype and genetic considerations. Acta Derm Venereol 2008;88:607-12

10. Perret C. Schöpf syndrome. Br J Dermatol 1989; 120: 131-132.

11. Bohring, A., Stamm, T., Spaich, C., Haase, C., Spree, K., Hehr, U., Hoffmann, M., Ledig, S., Sel, S., Wieacker, P., Ropke, A. WNT10A mutations are a frequent cause of a broad spectrum of ectodermal dysplasias with sex-biased manifestation pattern in heterozygotes. Am. J. Hum. Genet.2009; 85: 97-105. 